\title{
RESILIÊNCIA NA HABITAÇÃO SOCIAL: AVALIAÇÃO PÓS-OCUPAÇÃO DA FLEXIBILIDADE
}

VISBQP

UBERLÂNDIA 2019

\author{
PARREIRA, Fernanda Vilela Martins \\ Universidade Federal de Uberlândia, e-mail: fernandavmp@yahoo.com.br \\ VILLA, Simone Barbosa \\ Universidade Federal de Uberlândia, e-mail: simonevilla@ufu.br
}

\begin{abstract}
RESUMO
Diante dos desafios e limites do programa Minha Casa Minha Vida, torna-se fundamental a resiliência no ambiente construído, entendido como a capacidade de absorver e transformar aos diversos impactos ao longo do tempo. A flexibilidade espacial pode ser considerada como um atributo para conferir resiliência. Apesar de não se fazer presente nos projetos do PMCMV, estratégias de flexibilidade são identificadas nas moradias numa tentativa intuitiva de ampliar a adaptabilidade do lugar. A pesquisa de mestrado em curso tem como objetivo avaliar o atributo da flexibilidade espacial através da análise de projetos e da avaliação pós-ocupação em estudos de caso na cidade de Uberlândia e direcionar os resultados da pesquisa de forma pratica e direta ao usuário e sua assistência técnica, utilizando-se para isso ferramentas computacionais mais interativas. O presente artigo apresenta parte dos resultados obtidos na pesquisa, relatando sua fundamentação teórica, a definição dos instrumentos de avaliação da APO e os resultados preliminares da avaliação dos impactos percebidos em um estudo de caso. A pesquisa pretende avançar na área em três medidas principais: (i) analisar a flexibilidade como um atributo da resiliência no ambiente construído focado no ponto de vista dos usuáriosmoradores identificando suas capacidades adaptativas; (ii) desenvolver instrumentos tecnológicos e aplicativos de APO para sua análise e disponibilização dos resultados; (iii) contribuir de forma prática e direta ao usuário e sua assistência técnica.
\end{abstract}

Palavras-chave: Resiliência no ambiente construído, Flexibilidade espacial, Habitação de interesse social, Avaliação pós-ocupação.

\begin{abstract}
Faced with the challenges and limits of the Minha Casa Minha Vida program, resilience in the built environment is fundamental, understood as the capacity to absorb and transform the various impacts over time. Spatial flexibility can be considered as an attribute to impart resilience. Although not present in the PMCMV projects, flexibility strategies are identified in the dwellings in an intuitive attempt to increase the adaptability of the place. The current master's research aims to evaluate the attribute of spatial flexibility through project analysis and post-occupation evaluation in case studies in the city of Uberlândia and to direct the results of the research in a practical and direct way to the user and their assistance using more interactive computational tools. The present article presents some of the results obtained in the research, reporting its theoretical basis, the definition of the APO evaluation instruments and the preliminary results of the evaluation of the impacts perceived in a case study. The research intends to advance the area in three main measures: (i) to analyze flexibility as an attribute of resilience in the built environment focused on the point of view of the user-dwellers identifying their adaptive capacities; (ii) develop technological tools and APO applications for analysis and availability of results; (iii) contribute in a practical and direct way to the user and his technical assistance.
\end{abstract}

Keywords: Resilience in the built environment, Spatial flexibility, Social housing, Post-occupation evaluation.

PARREIRA, F. V. M.; VILLA, S. B. Resiliência na habitação social: avaliação pós-ocupação da flexibilidade. In: SIMPÓSIO BRASILEIRO DE QUALIDADE DO PROJETO NO AMBIENTE CONSTRUÍDO, 2019, 6., Uberlândia. Anais... Uberlândia: PPGAU/FAUeD/UFU, 2019. p. 1377-1389. DOI https://doi.org/10.14393/sbqp19124. 


\section{INTRODUÇÃO}

O Governo Federal lançou o Programa Minha Casa Minha Vida (PMCMV) em 2009 como tentativa de suprir o déficit habitacional e como estímulo à economia frente à crise econômica mundial. Com esse investimento, foram contratadas 4,44 milhões de unidades habitacionais de interesse social (HIS) até dezembro de 2016, sendo o maior investimento e o maior volume em relação a habitação social produzido no Brasil em curto espaço de tempo (INSTITUTO ESCOLHAS, 2019). Conforme estudo, a opção sempre recaiu mais na quantidade de produção de HIS, do que na qualidade, onde aspectos mínimos de habitabilidade, funcionalidade e privacidade não são atendidos (AMORIM et al., 2015). Assim, são evidentes as problemáticas desde a concepção projetual dessas edificações, tais como espaços mínimos, manutenção do modelo tripartido de morar e um desenho espacial limitador, configurando em uma baixa flexibilidade espacial e resiliência no ambiente construído. Os CHIS têm demonstrado uma baixa capacidade de resposta aos impactos e demandas que os moradores sofrem ao longo dos anos, aumentando, portanto, sua vulnerabilidade social, física e ambiental (VILLA et al., 2017).

A flexibilidade tem sido objeto de estudo nos últimos 20 anos, principalmente na avaliação de programas habitacionais. Em um mapeamento da produção científica brasileira quanto ao conceito de flexibilidade, foram constatados que $86 \%$ dos trabalhos tratam da flexibilidade na habitação, sendo $48 \%$ de HIS térrea, $19 \%$ HIS apartamento. Desse total os objetivos dos trabalhos podem ser classificados como: $27 \%$ com objetivo de propor estratégias, diretrizes ou propostas de projetos flexíveis; $27 \%$ buscam compreender conceitos, soluções e atributos de flexibilidade; $23 \%$ avaliar a qualidade/desempenho da edificação e/ou satisfação do usuário (LOGSDON; COSTA; FABRICIO, 2018). O diferencial dessa pesquisa é a intenção de levantar e gerar estratégias de flexibilidade voltada para o usuário, no qual os próprios moradores possam solucionar problemas que eles estão vivenciando na residência. As reformas já são realizadas na residência, mas acontecem sem assistência técnica, de forma intuitiva gerando em muitos casos problemas no ambiente construído. Na pesquisa RESAPO 80\% fizeram ampliação, 47,5\% reformaram para resolver problemas (VILLA et al., 2017)

Nesse cenário deficitário, onde existe uma produção de moradia em massa que não visa qualidade, e com uma população de baixa renda que sofrem diversos impactos, é fundamental a resiliência no ambiente construído. Entendendo resiliência como a capacidade de absorver e transformar os diversos impactos ao longo do tempo (GARCIA; VALE, 2017). Essa pesquisa entende que 0 ambiente construído possui atributos que the conferem resiliência. Um desses atributos é a flexibilidade, entendido como a capacidade do ambiente de se adaptar às necessidades de mudanças dos usuários (SCHNEIDER; TILL, 2005). A flexibilidade é colocada pelas produções cientificas como uma forma de solucionar os problemas da HIS, porém, não tem sido incorporado pelos projetos.

Esse trabalho de mestrado está baseado no estudo da resiliência no ambiente construído em HIS, com enfoque para a flexibilidade espacial das habitações. Difere-se dos trabalhos já realizados sobre o tema, na medida em que tem como foco o usuário-morador, suas percepções e soluções realizadas nos espaços caracterizadas como capacidades adaptativas. Pretende avaliar o 
atributo da flexibilidade através da análise de projetos e da Avaliação Pósocupação (APO) em estudos de caso e direcionar os resultados da pesquisa de forma prática e direta ao usuário e sua assistência técnica. O trabalho se insere em um projeto de pesquisa em curso, financiado pelo CNPq, intitulado [BER HOME] Resiliência no ambiente construído em habitação social: métodos de avaliação tecnologicamente avançados, desenvolvida no Grupo MORA Pesquisa em Habitação da Faculdade Arquitetura e Urbanismo e Design (FAUeD). O presente artigo apresenta parte dos resultados desse trabalho em desenvolvimento, enfocando sua revisão bibliográfica, a definição dos conceitos e métodos a serem aplicados na APO dos estudos de caso, assim como resultados preliminares da avaliação de impactos percebidos em um estudo de caso.

\section{METODOLOGIA}

A metodologia adotada para o escopo é o Design Science Research (DSR), que tem como finalidade estudar, objetivar e pesquisar o projeto, onde a solução é dada por meio da concepção de artefatos. O artefato da pesquisa é um ambiente Web, o qual consiste no conjunto de métodos de avaliação e a disponibilização dos resultados da pesquisa orientado para o usuário. 0 conhecimento da DSR é prescritivo, sendo no caso orientada a solução tanto para o usUário (DRESCH; LACERDA; ANTUNES JÚNIOR, 2015). As primeiras fases da pesquisa consistem em (i) identificação e conscientização do problema; (ii) revisão bibliográfica acerca da flexibilidade em HIS como atributo da resiliência no ambiente construído; (iii) desenvolvimento do artefato por meio dos indicadores de flexibilidade, as análises de projeto e a identificação de impactos. A fase seguinte da pesquisa consiste na $\mathrm{APO}^{1}$ de dois Estudos de Caso, onde são levantados os instrumentos a serem aplicados, sendo o primeiro deles apresentado nesse artigo que é o questionário de avaliação de impacto.

O questionário é um instrumento de coleta de dados que averigua a opinião do usuário. Consiste em um instrumento de levantamento de dados, onde se tem um roteiro estruturado com perguntas padronizadas, com o objetivo de fornecer dados relevantes para representar e generalizar uma certa população. (ONO, 2019) O Grupo [MORA] tem avançado na pesquisas voltadas na Inovação Tecnológica ${ }^{2}$ através do desenvolvimento de instrumentos de APO em interfaces digitais.

Ambos os estudos de caso analisados em Uberlândia são faixa 1 do PMCMV, sendo um horizontal denominado de Sucesso Brasil, e o segundo vertical denominado de Córrego do Óleo. A Aplicação de questionários na APO será por meio de instrumentos computacionais, sendo a primeira etapa uma avaliação de impactos. Posteriormente serão adotados outros instrumentos para entender como acontece a capacidade adaptativa dos moradores e quais são as estratégias de flexibilidade.

\footnotetext{
1 Protocolo CEP 20239019.5.0000.5152.

2 Inovação tecnológica grupo MORA, disponível em: <https://morahabitacao.com/pesquisasem-andamento-2/inovacao-tecnologica-tecnologic-innovation/>.
} 


\section{FUNDAMENTAÇÃO TEÓRICA}

\subsection{Flexibilidade como atributo de resiliência}

Resiliência é um termo muito utilizado no cenário global pelas grandes agendas, como a Nova Agenda Urbana (2017) e objetivos de desenvolvimento sustentável da ONU (2015), que entendem a resiliência como uma força capaz de combater a vulnerabilidade causada por questões sociais, ambientais e urbanas. A pesquisa produzida pela EY e 100 resilient cities (2019) reforça que a HIS é componente essencial para a resiliência urbana e que a resiliência deveria começar pela moradia. A resiliência no ambiente construído é a capacidade do ambiente de se adaptar e transformar para lidar positivamente com impactos impostos ao longo do tempo. Crises comuns afetam a capacidade de resiliência do ambiente construído por se tratar de questões do cotidiano (GARCIA; VALE, 2017).

Como meio de conferir e facilitar a resiliência, consideramos a flexibilidade como um atributo, pois permite ao usuário transformar sua residência conforme suas necessidades. É defendido tanto a flexibilidade inicial como a permanente, sendo justificada pela necessidade contínua de modificações (BRANDÃO; HEINECK, 2003). De acordo com Schneider e Till (2005), a Habitação flexível é a que se adapta às necessidades de mudança do usuário. Podendo fazer alterações antes do uso e posteriormente, conforme a necessidade do usuário. É um atributo relacionado a qualidade espacial da habitação, mas que pode ser uma resposta para a ampliação da vida útil do edifício, nos atendimentos às mudanças do núcleo e da dinâmica familiar, assim como na saúde econômica e ambiental do edifício (LOGSDON, 2017).

Digiacomo (2004) elenca questões importantes ao ter uma flexibilidade em HIS: existência de tipologias familiares diversas, assim como a coabitação; usuários com modos de vida, rotina e hábitos diferentes; diversidade cultural; existência de novas tecnologias permitindo a possibilidade de pessoas trabalharem em casa e a existência de empreendedores que usam a casa como local de serviço; realizar diversas atividades. O custo em reforma para os moradores é impactante no orçamento familiar, então quanto mais flexível uma habitação, mais fácil e menor será o gasto para as adaptações e ampliações e por consequência melhor a qualidade da habitação (DIGIACOMO, 2004).

\subsection{Instrumentos de avaliação da APO}

Em um primeiro momento, a APO será na verificação dos problemas e impactos nos dois estudos de caso por meio da aplicação de questionário. $O$ impacto sobre o ambiente construído deriva de causas que geram ameaças e como consequência, efeitos negativos. Os moradores raramente conseguem perceber a causa ou a ameaça, pois o que percebem são os efeitos negativos, são os incômodos gerados dia-a-dia em sua residência. Abaixo segue o quadro $1 \mathrm{com}$ as definições de impactos e suas referências conforme discutido na pesquisa [Ber_Home]. 


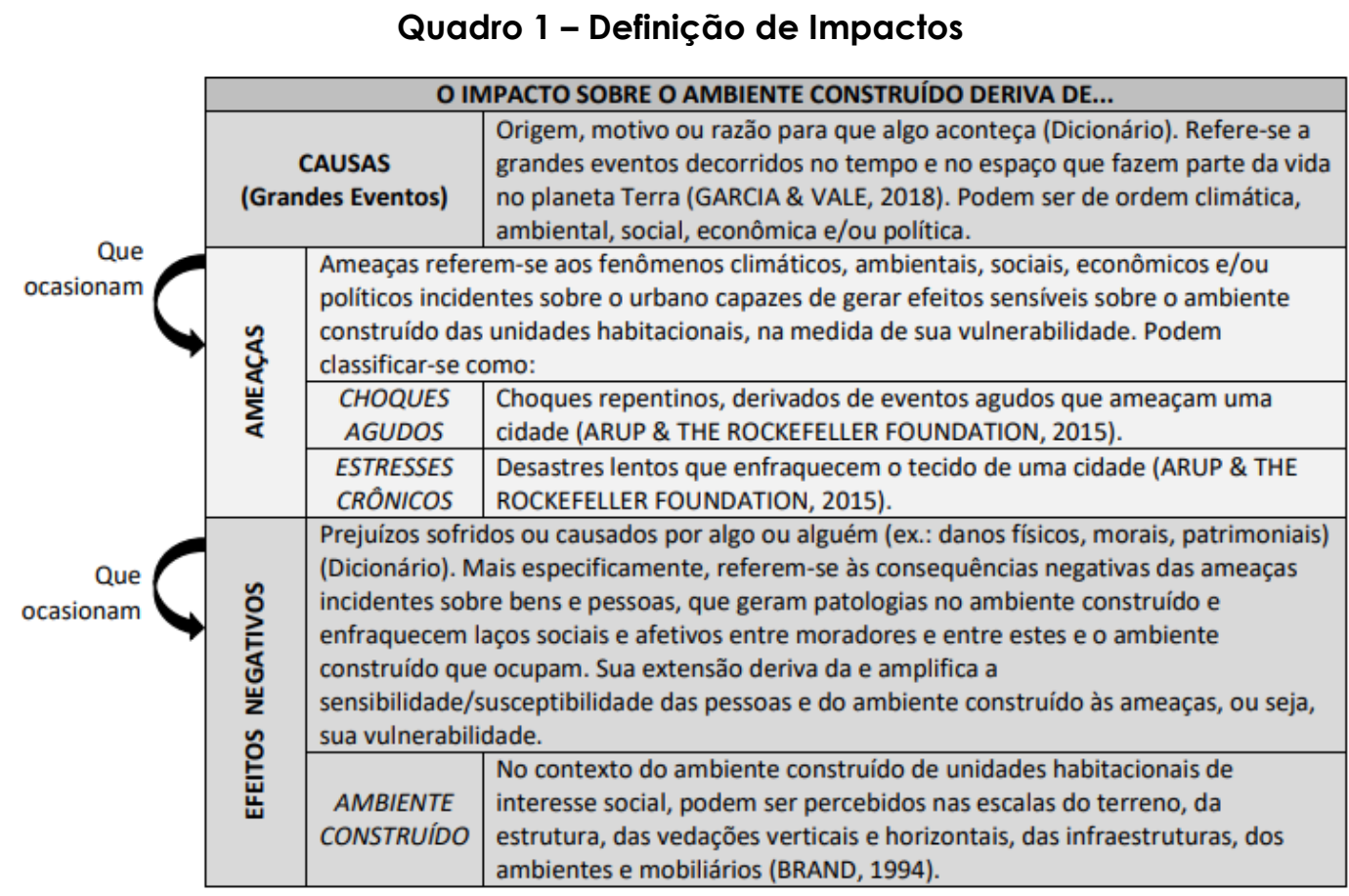

Fonte: Autoras (2019)

\subsection{Indicadores de flexibilidade}

A moradia após ser entregue e ocupada por seus moradores começa a se transformar e configurar conforme os impactos incidem. Nessa pesquisa é entendido que quanto maior a flexibilidade na habitação maior a resiliência do ambiente construído. Durante a pesquisa bibliográfica foram levantados alguns indicadores de flexibilidade, os quais ajudaria na capacidade de transformar o ambiente construído. Esses pré indicadores estão no quadro 2 e serão avaliados na segunda etapa da APO e em analises de projetos. Porém foram essenciais para elaborar as questões de causa, ameaça e efeito negativo relacionados a flexibilidade.

Quadro 2 - Pré Indicadores de flexibilidade

\begin{tabular}{|l|l|}
\hline \multicolumn{1}{|c|}{ INDICADORES } & \multicolumn{1}{c|}{ DEFINIÇÃo } \\
\hline AMPLIABILIDADE & Modificação da área habitacional - acréscimo de área ứtil \\
\hline ADAPTABILIDADE & Capacidade de adaptação da moradia após a construção \\
\hline MULTIFUNCIONALIDADE & Adaptação do cômodo para usos diversos \\
\hline POLIVALÊNCIA & Ambiente elástico \\
\hline CONVERSIBILIDADE & Mudança na configuração espacial dos cômodos \\
\hline VARIABILIDADE & Mudança na forma, dimensão; \\
\hline NEUTRALIDADE & Ajustar conforme as mudanças necessárias sem alterar elementos arquitetônicos; \\
\hline DIVERSIDADE & Diversidade tipológica; \\
\hline
\end{tabular}

Fonte: Autoras (2019)

O grande evento (Causa) relacionada a flexibilidade é o próprio modelo do PMCMV. Pois os indicadores de flexibilidade estão relacionado as dimensões dos cômodos, a configuração do espaço, a implantação no terreno, a técnica construtiva e os materiais utilizados relacionando diretamente ao projeto. E o programa prevê que o projeto esteja dentro do modelo fornecido por eles, não permitindo grandes alterações. Diante dessa causa, podemos listar algumas ameaças verificadas que afetam os moradores. 


\subsection{Resultado da avaliação de impacto}

O primeiro instrumento foi desenvolvido para identificar a percepção do usuário quanto aos impactos (incômodos). Nos quadros 3 e 4 abaixo, seguem as ameaças levantadas na pesquisa.

\section{Quadro 3 - Identificação de ameaças quanto a Flexibilidade espacial}

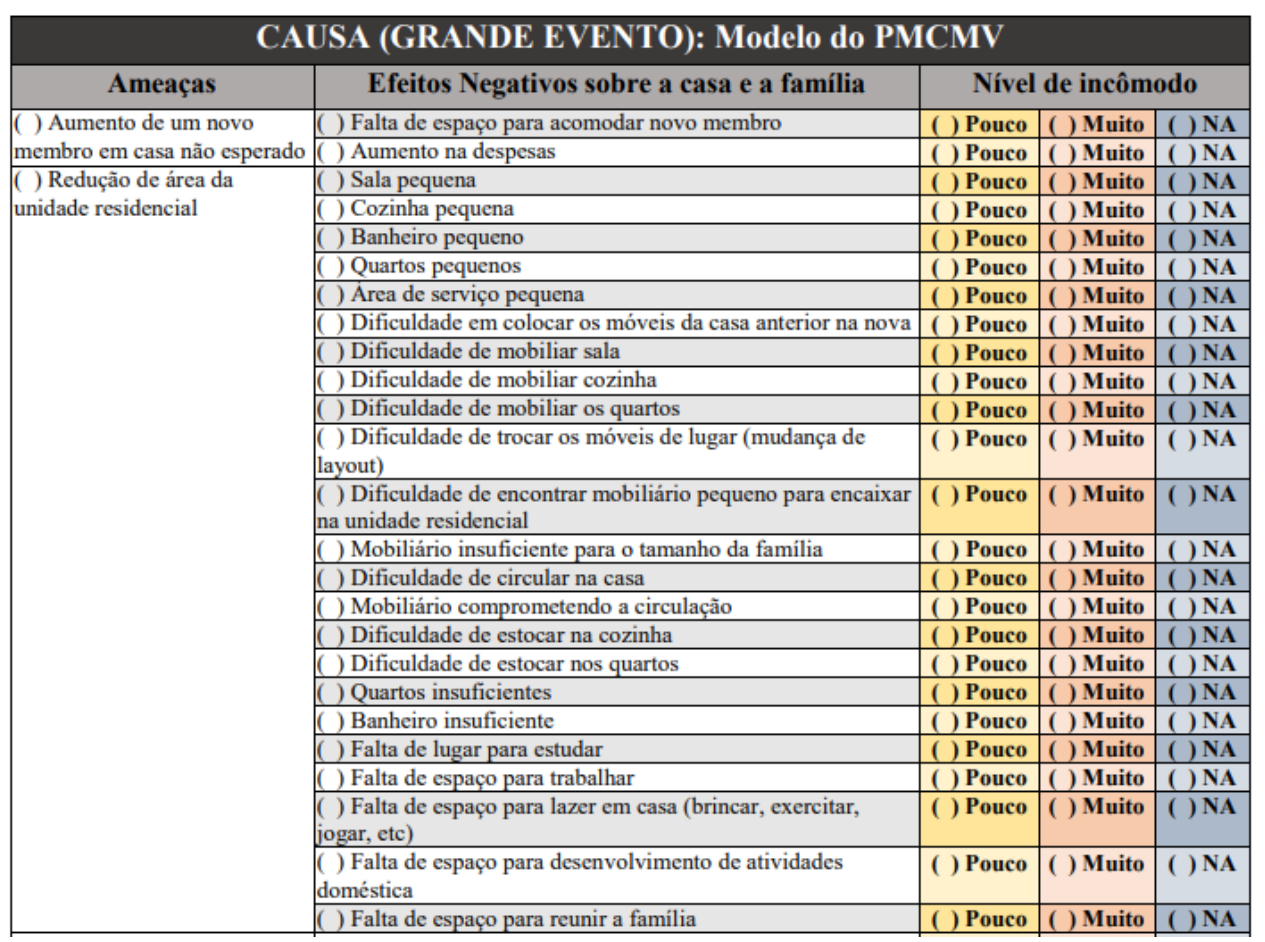

Fonte: Autoras (2019)

\section{Quadro 4 - Identificação de ameaças quanto a Flexibilidade espacial}

\begin{tabular}{|c|c|c|c|c|}
\hline \multirow{2}{*}{$\begin{array}{l}\text { ( ) Dificuldade em se adaptar } \\
\text { na unidade residencial }\end{array}$} & ( ) Falta de identidade com a unidade residencial & () Pouco & ( ) Muito & () $\mathbf{N A}$ \\
\hline & ( ) Dificuldade em se adaptar a casa & () Pouco & ( ) Muito & ( ) NA \\
\hline \multirow{5}{*}{$\begin{array}{l}\text { ( ) realização de muitas } \\
\text { atividades em um mesmo } \\
\text { cômodo }\end{array}$} & ( ) Falta de privacidade entre os moradores & ( ) Pouco & ( ) Muito & ( ) NA \\
\hline & ( ) Dificuldade em realizar tarefas que exige concentração & () Pouco & () Muito & ( ) NA \\
\hline & $\begin{array}{l}\text { ( ) Dificuldade em realizar atividades que goste por falta de } \\
\text { privacidade }\end{array}$ & ( ) Pouco & ( ) Muito & ( ) NA \\
\hline & ( ) Muita Sobreposição de atividade de forma insuficiente & ( ) Pouco & ( ) Muito & ( ) NA \\
\hline & () Problema de convivência familiar & () Pouco & ( ) Muito & ( ) NA \\
\hline \multirow[t]{8}{*}{ ( ) Baixo padrão construtivo } & ( ) Falta de privacidade entre vizinhos & () Pouco & ( ) Muito & ( ) NA \\
\hline & ( ) Má convivência com o vizinho & () Pouco & ( ) Muito & ( ) NA \\
\hline & ( ) Reformas constantes & () Pouco & () Muito & ( ) NA \\
\hline & ( ) Problemas construtivos (trinca, rachadura...) & () Pouco & () Muito & ( ) NA \\
\hline & ( ) Problemas nas instalações elétricas, hidráulica ou esgoto & ( ) Pouco & ( ) Muito & ( ) NA \\
\hline & ( ) Parede autoportante, não podendo ser demolida e realocada & ( ) Pouco & ( ) Muito & ( ) NA \\
\hline & \begin{tabular}{|l|l|} 
( ) Problemas com portas e esquadrias \\
\end{tabular} & () Pouco & ( ) Muito & ( ) NA \\
\hline & ( ) Excessos de ruídos externos ( barulho na rua e vizinhos) & () Pouco & ( ) Muito & ( ) NA \\
\hline \multirow{4}{*}{$\begin{array}{l}\text { ( ) Não possui previsão de um } \\
\text { cômodo a mais para } \\
\text { trabalho/comércio/serviço }\end{array}$} & ( ) Dificuldade em adaptar cômodo da casa para trabalhar & () Pouco & ( ) Muito & ( ) NA \\
\hline & ( ) Uso ineficiente de um dos cômodos para trabalhar & () Pouco & ( ) Muito & ( ) NA \\
\hline & ( ) Espaço insuficiente para armazenar materiais de trabalho & () Pouco & ( ) Muito & ( ) NA \\
\hline & ( ) Ampliação de cômodo comercial sem assistência técnico & ( ) Pouco & ( ) Muito & ( ) NA \\
\hline \multirow{9}{*}{$\begin{array}{l}\text { ( ) Reforma sem Assistência } \\
\text { Técnica }\end{array}$} & ( ) Obstrução de aberturas & () Pouco & () Muito & ( ) NA \\
\hline & () Alto gasto em reformas & ( ) Pouco & ( ) Muito & ( ) NA \\
\hline & $\begin{array}{l}\text { ( ) Ausência de armazenamento adequado de materiais de } \\
\text { reforma }\end{array}$ & ( ) Pouco & ( ) Muito & ( ) NA \\
\hline & ( ) Alta produção de lixo devido a reformas & () Pouco & ( ) Muito & ( ) NA \\
\hline & ( ) Ampliação inadequada & () Pouco & ( ) Muito & ( ) NA \\
\hline & ( ) Baixa qualidade do serviço de reforma & ( ) Pouco & ( ) Muito & ( ) NA \\
\hline & ( ) Aumento dos problemas construtivos decorrido da reforma & ( ) Pouco & ( ) Muito & ( ) NA \\
\hline & \begin{tabular}{|l|l} 
( ) Desperdício de materiais construtivos \\
\end{tabular} & ( ) Pouco & ( ) Muito & ( ) NA \\
\hline & ( ) Demora para a realização de reformas & () Pouco & ( ) Muito & ( ) NA \\
\hline
\end{tabular}


Esse instrumento foi aplicado no estudo de caso Residencial Sucesso Brasil no Shopping Park em Uberlândia, composto por 175 lotes. Foi aplicado 0 questionário de impacto em 40 casa, sendo aproximadamente $23 \%$ dos lotes. O projeto é de casas geminadas, com a implantação espelhada, de forma que a parede que divide as casas são as dos quartos, conforme Figura 1.

$$
\mid
$$

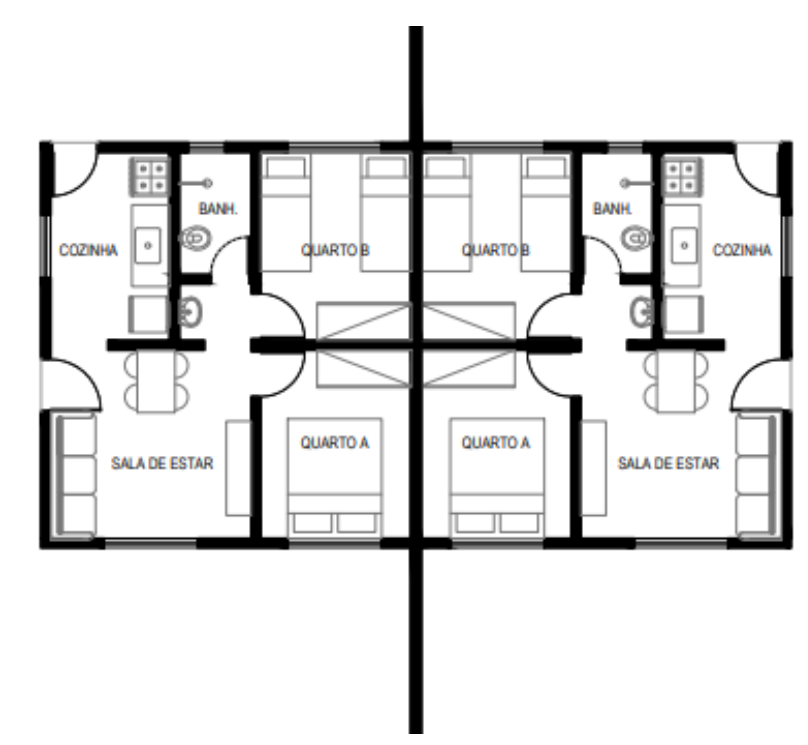

Figura 1 - Implantação das casas -

Fonte: Autoras (2019)

Uma das ameaças é que o perfil familiar varia muito, seja com o nascimento de mais um membro da família ou seja pela vinda de parentes ou conhecidos residir na mesma casa, dados no Gráfico 1. 38\% consideraram que aumentaram nas despesas e $28 \%$ de que faltava espaço para acomodar esse novo membro.

\section{( ) Aumento de um novo membro em casa não esperado}

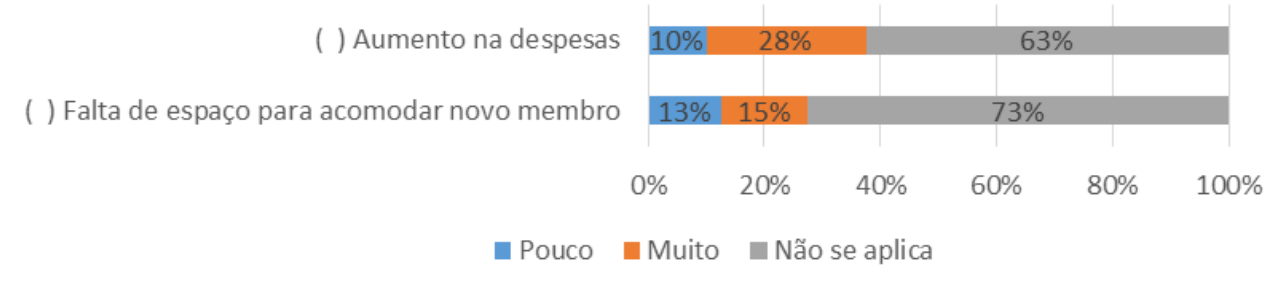

\section{Gráfico 1 - Ameaça 1 -}

Fonte: Autoras (2019)

A redução da área dimensional da residência é a segunda ameaça analisada e os dados são apresentados no Gráfico 2. Como percepção dos usuários, o menor cômodo é a cozinha, sendo $90 \%$ consideram pesqueno. O segundo seria o banheiro onde $72 \%$ consideram pequeno, e em seguida os quartos com $72 \%$. A área de serviço que na tipologia de casa não é um cômodo fechado, mas sim encostado na parede e coberto pelo beiral temos $70 \%$. A sala é o cômodo que gera menor incômodo sendo $38 \%$ que acham muito pequeno e $35 \%$ pouco pequeno. Os cômodos os quais acontecem intervenção são a área de serviços e a troca aa cozinha de dentro da casa para a varanda. 


\section{( ) Redução de área da unidade residencial}

( ) falta de espaço para reunir a família

( ) falta de espaço para desenvolvimento de...

( ) falta de espaço para lazer em casa

( ) falta de espaço para trabalhar

( ) falta de lugar para estudar

( ) Banheiro insuficiente

( ) Quartos insuficientes

( ) Dificuldade de estocar nos quartos

( ) Dificuldade de estocar na cozinha

( ) Mobiliário comprometendo a circulação

( ) Dificuldade de circular na casa

( ) Mobiliário insuficiente para o tamanho da família

( ) Dificuldade de encontrar mobiliário pequeno.

( ) Dificuldade de trocar os móveis de lugar

( ) Dificuldade de mobiliar os quartos

( ) Dificuldade de mobiliar cozinha

( ) Dificuldade de mobiliar sala

( ) Dificuldade em colocar os móveis da casa..

( ) Área de serviço pequena

( ) Quartos pequenos

( ) Banheiro pequeno

( ) Cozinha pequena

( ) Sala pequena
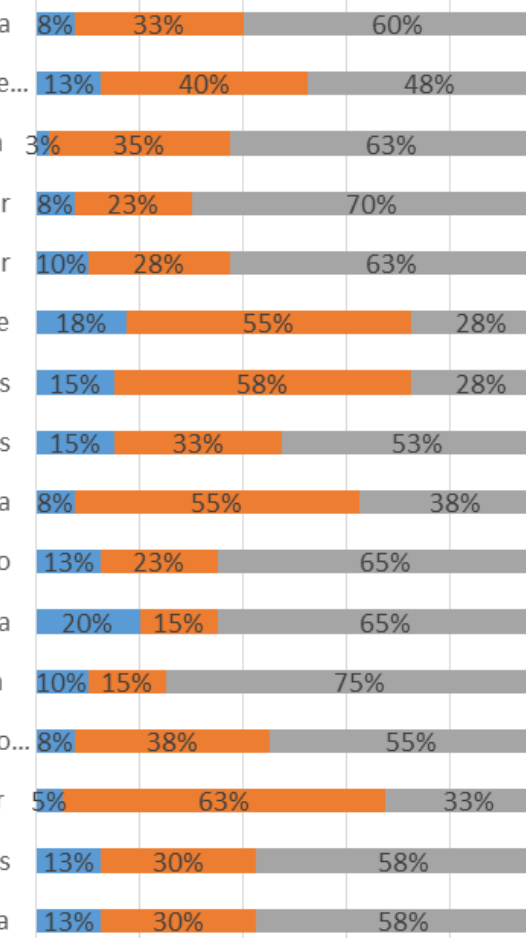

\section{3}
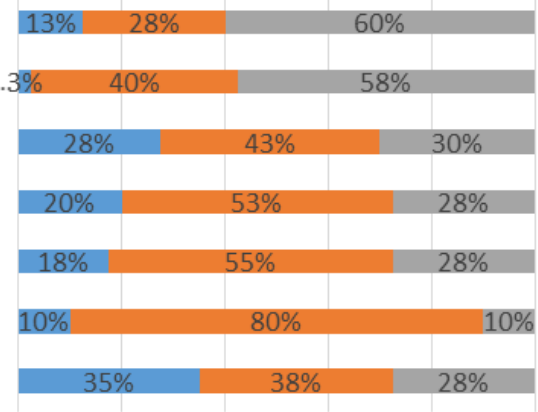

$0 \% \quad 20 \% \quad 40 \% \quad 60 \% \quad 80 \% \quad 100 \%$

- Pouco Muito não se aplica

\section{Gráfico 2 - Ameaça 2 -}

Fonte: Autoras (2019)

A dificuldade de colocar os móves da casa antiga na nova foi de $42 \%$ da população. A dificuldade de mobiliar os cômodos como sala, quarto e cozinha, em torno de $42 \%$ e $40 \%$ tiveram problema. Quanto a dificuldade de trocar os móveis de lugar, considerado um dos indicadores de flexibilidade que seria a troca de layout, $67 \%$ consideram dificil trocar, indicando uma baixa flexibilidade da planta proposta. Somente $45 \%$ encontrarm dificuldade em encontrar móveis pequenos no mercado. Quanto ao mobiliário insuficiente para o tamanho da familia somente $25 \%$ consideram insuficientes. A percepção dos usuários é de $35 \%$ possuem dificuldade de circular na casa. $O$ mobiliário compromentendo a circulação foi um efeito negativo apontado considerando que em muitos casos os moradores aproveitam os mobiliários antigos e que podem ser maior do que o ideal para aquela área. Quanto a esse fator $35 \%$ consideram que o mobiliário prejudica a circulação. 
Um dos itens que fica comprometido nos cômodos quando se reduz as dimensões é a capacidade de estocagem. Foi considerando 2 grandes áreas na analise de estocagem que é a cozinha, por ter muitos utensilios e mantimentos, e os quartos por armazenar todos os itens de uso pessoal dos moradores. Na cozinha foram $62 \%$ que relataram ter dificuldade para estocar. Nos quartos o múmero já diminui para $47 \%$. Quanto a quantidade de quartos e banheiro, $72 \%$ consideram insuficiente. Esse valor alto justifica as ampliações realizadas sem assistência técnica.

Foram consideradas algumas atividades comumentes realizadas em casa e foi questionado aos moradores se sentiam falta de espaço pra realizar essas atividades. Para atividades como estudar, trabalhar, lazer em casa e reunir a família a quantidade que possui esse problema é de $30 \%$ á $40 \%$. A atividades que os moradores mais percebem no dia a dia são o desenvolvimento de atividade doméstica com $52 \%$ sentem falta de espaço, justificando o alto incômodo em relação ao tamanho da cozinha e da ampliação da área de serviço coberta.

A flexibilidade permite uma maior capacidade do usuário transformar a unidade residencial conforme rotinas, costumes, identidade e perfil familiar e a dificuldade em se adaptar se relaciona com essa falta de flexibilidade. Nesse fator $62 \%$ tiveram dificuldade para se adaptar a unidade residencial. E quanto a falta de identidade com a casa foi de $55 \%$ que não possuia alguma identidade. Configurando a ameaça 3, apresentada no gráfico 3.

\section{( ) Dificuldade em se adaptar na unidade residencial}

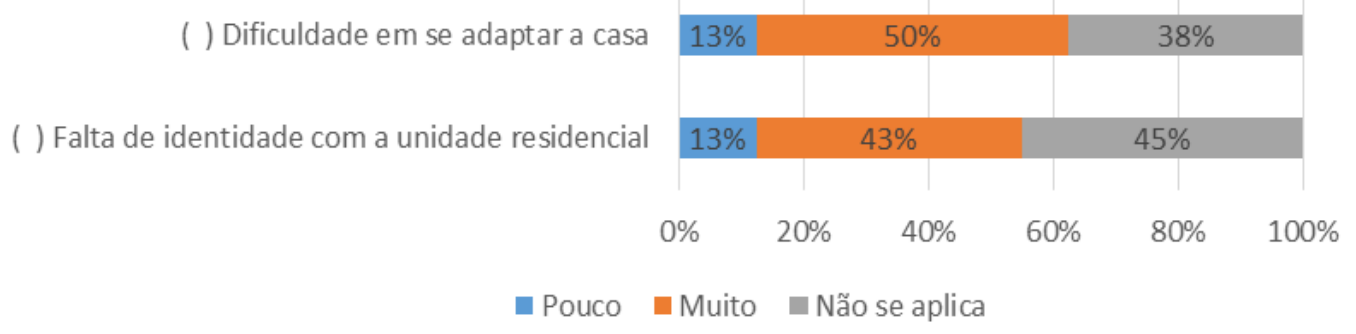

Gráfico 3 - Ameaça 3 -

Fonte: Autoras (2019)

A quarta ameaça apontada no Gráfico 4 é a realização de muitas atividades em um mesmo cômodos de forma insuficiente. A capacidade de sobreposição de atividades, na conceituação de flexibilidade, é um fator positivo, desde que o espaço permita essa sobreposição de forma eficiente, o que muitas vezes não acontecem. Em torno de $27 \%$ á $30 \%$ sofrem com essa ameaça, sendo que seus efeitos negativos são a falta de privacidade entre os moradores, dificuldade em realizar tarefas que exigem concentração, dificuldade em realizar tarefas que goste por falta de privacidade, muita sobreposição de atividade de forma insuficiente e problema de convivência familiar.

A ameaça 5 que é o baixo padrão construtivo foram analizados os problemas encontrados na residência e os dados apresentados no Gráfico 5. É importante analisar algumas questões que influenciam na capacidade de configurar o ambiente, de ampliar a unidade residencial ou até de transformar 
seu uso. Como as casas são geminadas de duas em duas, a parede que divide as casas não foi realizada até a cuminheira fazendo com que exista uma falta de privacidade, onde $87 \%$ possuem problema com a falta de privacidade. $72 \%$ fizeram reformas constantes para resolver problema. Um dos fatores analisados é se a parede ser autoportante traz incômodo para os moradores e $80 \%$ tem algum incômodo quanto a ela, no qual dificulta as modificações.Assim como as instalações embutidas na parede também não permites essa flexibilidade.

\section{( ) realização de muitas atividades em um mesmo cômodo}
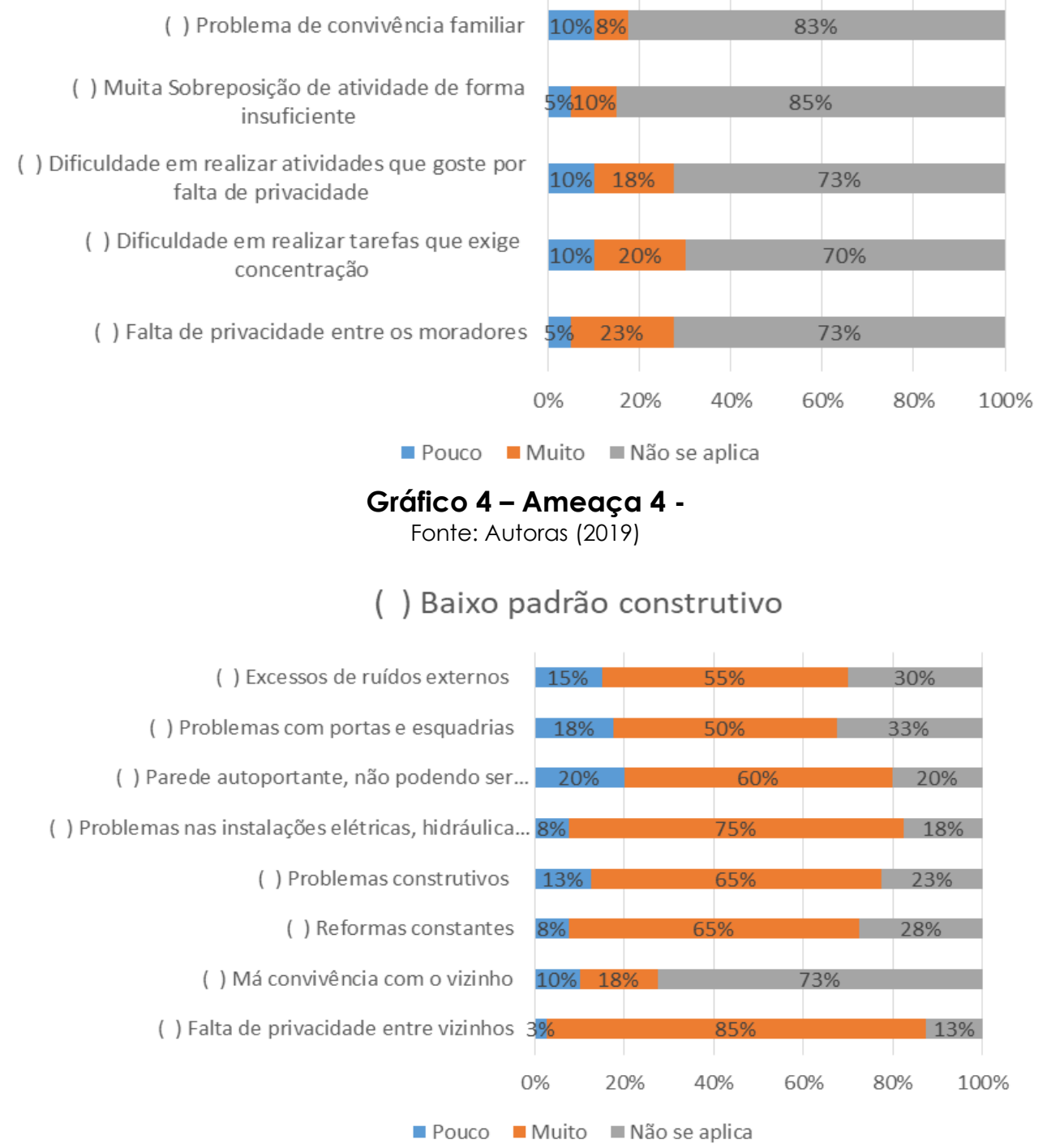

Gráfico 5 - Ameaça 5 -

Fonte: Autoras (2019)

A reforma sem assistência técnica é um problema sério porque em muitos casos ela acaba gerando mais problemas ou agravando aqueles que 0 morador tentou solucionar, sendo portanto a ameaça 6 e os dados no Gráfico 6. Por isso justifica o trabalho da dissertação ser voltado para o usuários, de propor soluções orientada para a ampliação da flexibilidade e da resiliência. Quanto a obstrução de aberturas somente $30 \%$ consideraram que obstruíram, como a casa é geminada e o lote estreito e comprido, a ampliação sem uma 
assistência técnica leva a gerar cômodos com janela para outro cômodo. $\bigcirc$ alto gasto em reforma é de $67 \%$ o incômodo. A alta produção de lixo devido a reforma foi de 50\% o incômodo. Ao baixo serviço de reforma, 35\% consideraram que tiveram esse incômodo. A demora para a realização das reformas foi considerado algum tipo de incômodo para $50 \%$ dos moradores.

\section{( ) Reforma sem Assistência Técnica}

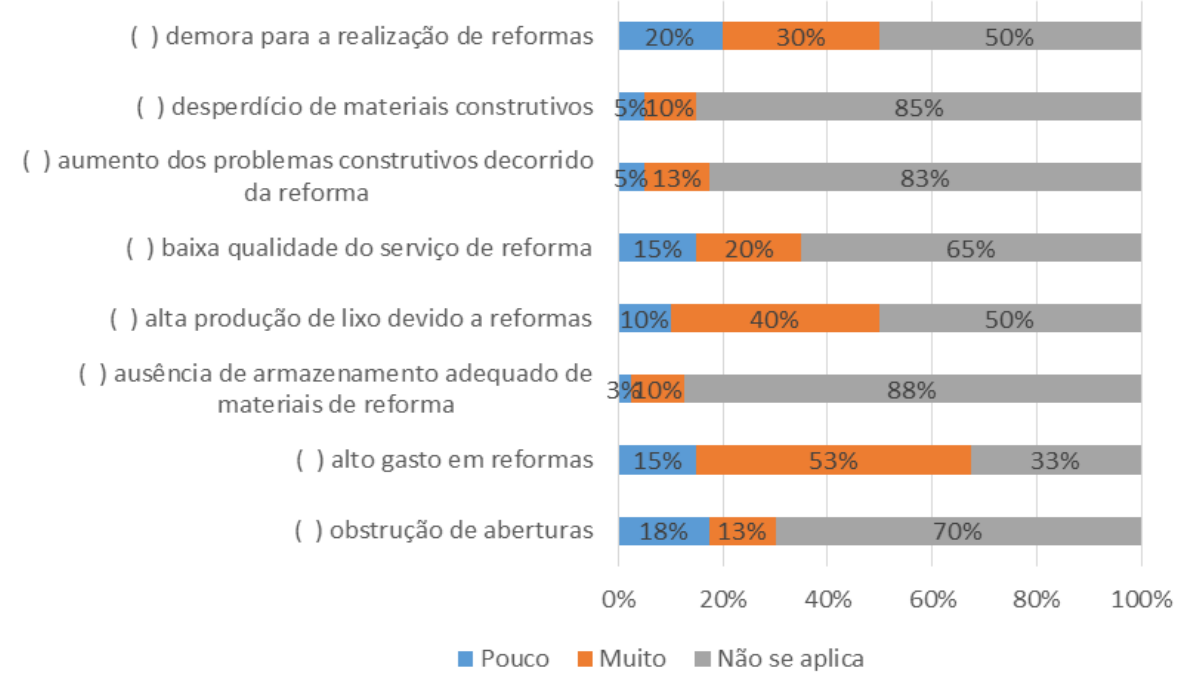

Gráfico 6 - Ameaça 6 -

Fonte: Autoras (2019)

A ameaça 7 apresentada no gráfico 7 foi considerada somente para as pessoas que trabalham em casa e/ou fizeram um cômodo comercial na frente da casa. $25 \%$ tiveram problema para adaptar algum cômodo da unidade residencial para trabalhar. $12 \%$ consideraram que o uso do comôdo foi ineficiente. $10 \%$ consideraram não ter espaço suficiente para armezar materiais de trabalho. $20 \%$ fizeram ampliação de um cômodo comercial sem assistência técnica. O trabalho em casa geralmente é uma forma de completar a renda familiar e também uma forma de superar desemprego.

\section{( ) Não possui previsão de um cômodo a mais para trabalho/comércio/serviço}

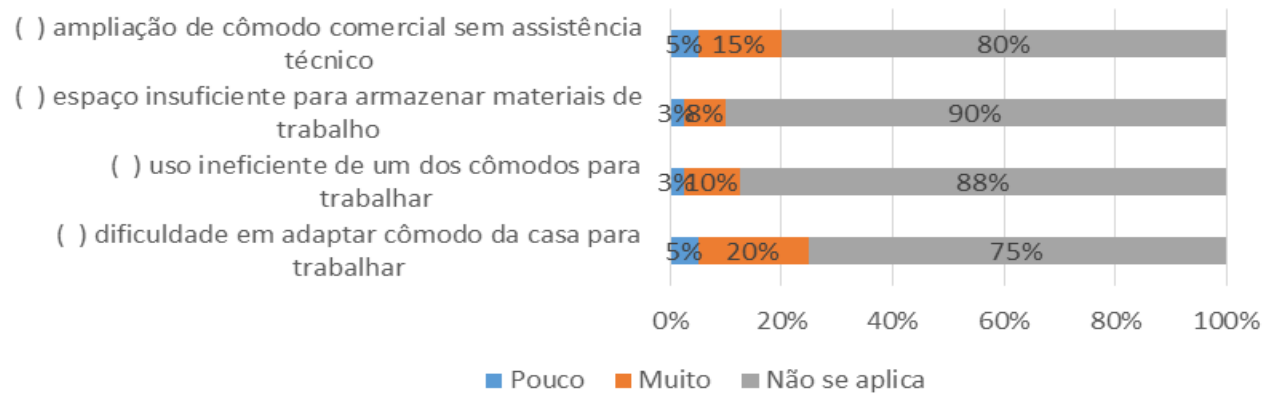

\section{Gráfico 7 - Ameaça 7 -}

Fonte: Autoras (2019)

Os impactos aos quais esses moradores tem que resistir são vários e vão modificando ao longo do tempo. A segunda parte do trabalho consiste na capacidade adaptativa desses moradores e das moradias, como eles 
enfrentam esses impactos e como isso transforma a vida deles e portanto chegar em como é a capacidade de resiliência desse ambiente construído.

\section{CONSIDERAÇÕES FINAIS}

Os dados levantados por essa primeira parte são importantes para diagnosticar e comprovar que os impactos aos quais esses moradores são inseridos são constantes e são importantes para dar base na continuidade da pesquisa. Se os impactos são constantes é necessário analisar qual é a capacidade adaptativa e posteriormente conseguir desenvolver um pacote de estratégias voltados para o usuário, como forma de modificarem o ambiente construído de forma positiva.

Diante do volume de HIS edificadas no Brasil, é necessário avaliar o que está sendo entregue para essa população, mas pensando principalmente em como solucionar os problemas encontrados. A resiliência surge como um agente essencial ao entender que consiste na capacidade de se adaptar e de se transformar frente aos problemas. E considerando a variedade de tipologias familiares e suas diversificações de necessidades, a flexibilidade se torna atributo essencial para essa capacidade adaptativa. Se faz necessário avaliar os impactos, os atributos e indicadores em loco e a partir disso propor soluções. O trabalho pretende avançar nas soluções práticas sobre a flexibilidade dos espaços no sentido de ampliar a resiliência social e física no ambiente construído. As informações serão destinadas aos próprios moradores e pautadas em suas experiências juntamente com recomendações técnicas mais precisas e adequadas.

Nesse sentido a pesquisa pretende como resultado final promover uma real e prática mudança na qualidade de vida dos moradores por meio do desenvolvimento de uma plataforma web, em que o morador consiga ter fácil acesso e entendimento.

\section{REFERÊNCIAS}

AMORIM, C. N. D. et al. Qualidade de Projeto arquitetônico. In: BLUMENSCHEIN, R. N.; PEIXOTO, E. R.; GUINANCIO, C. (orgs.). Avaliação da qualidade da

habitação de interesse social: projetos urbanístico e arquitetônico e qualidade construtiva. Brasilia: UnB - FAU, 2015. p. 100-139.

ARUP; THE ROCKEFELLER FOUNDATION. City Resilience Index, 2015, 16 p.

Disponível em:

<https://www.arup.com/perspectives/publications/research/section/cityresilien ce-index>. Acesso em: 01 jun. 2019.

BRANDÃO, D. Q.; HEINECK, L. F. M. Significado multidimensional e dinâmico do morar: compreendendo as modificações na fase de uso e propondo flexibilidade nas habitações sociais. Ambiente Construído, v. 3, n. 4, p. 35-48, 2003.

DIGIACOMO, M. C. Estratégias de projeto para a habitação social flexível. 2004. 163 f. Dissertação (Mestrado em Arquitetura e Urbanismo) - Universidade Federal de Santa Catarina, Florianópolis, 2004. 
DRESCH, A; LACERDA, D. P.; ANTUNES JUNIOR, J. A. V. Design Science Research: método de pesquisa para avanço da ciência e tecnologia. Porto Alegre: Bookman, 2015.

EY; 100 RESILIENT CITIES. Should resilience begin with the home? 2019. 20 p. Relatório. Disponível em <http://100resilientcities.org/wpcontent/uploads/2019/02/EY_100RC_Social-Housing-Report_FINAL.pdf>. Acesso em: 01 mar. 2019.

GARCIA, J. E; VALE, B. Unravelling Sustainability and Resilience in the Built Environment. Londres: Routledge, 2017.

INSTITUTO ESCOLHAS. Morar longe: o Programa Minha Casa Minha Vida e a expansão das Regiões Metropolitanas. Relatório: São Paulo: CEPESP/FGV; Instituto Escolhas, 2019.

LOGSDON, L. Qualidade habitacional: Instrumental de apoio ao projeto de moradias sociais. 2017. 223 f. Exame de qualificação (Doutorado em Arquitetura e Urbanismo) - Instituto de Arquitetura e Urbanismo, Universidade de São Paulo, São Carlos, 2017.

LOGSDON, L.; COSTA, H. A.; FABRICIO, M. M. Flexibilidade na arquitetura: Mapeamento sistemático de literatura em bases brasileiras. In: ENCONTRO NACIONAL DE TECNOLOGIA DO AMBIENTE CONSTRUÍDO, 17., 2018, São Paulo. Anais... Porto Alegre: ANTAC, 2018.

NOVA AGENDA URBANA. Habitat III, United Nations, 2017. Disponível em: <http://habitat3.org/wp-content/uploads/NUA-Portuguese.pdf>. Acesso em: 10 Out. 2018.

ONO, R.; ORNSTEIN, S. W.; VILLA, S. B.; FRANÇA, A. J. G. L. (Org.). Avaliação Pósocupação: na arquitetura, no urbanismo e no design: da teoria à prática. São Paulo: Oficina de Textos, 2018.

SCHNEIDER, T.; TILL, J. Flexible housing: the means to the end. Arq: Architectural Research Quarterly, v. 9, n. 3/4, p. 287-296, 2005.

OBJETIVOS DE DESENVOLVIMENTO SUSTENTÁVEL. General Assembly: Transformando nosso mundo: a Agenda 2030 para o desenvolvimento sustentável, United Nations, 2015. Disponível em:

<https://nacoesunidas.org/wp-content/uploads/2015/10/agenda2030-ptbr.pdf>. Acesso em: 8 out. 2018.

VILLA, S. B.; et al. Método de análise da resiliência e adaptabilidade em conjuntos habitacionais sociais através da avaliação pós-ocupação e coprodução. RELATÓRIO FINAL DE PESQUISA: Uberlândia: Universidade Federal de Uberlândia; Universidade de Sheffield, 2017. 